\title{
Ovarian steroid hormone production in a multiple ovulating male line and a single ovulating traditional line of turkeys
}

\author{
S. Buchanan, G. W. Robertson and P. M. Hocking* \\ Roslin Institute, Roslin, Midlothian EH25 9PS, UK
}

\begin{abstract}
Ovarian production of oestradiol and progesterone was investigated in a single ovulating traditional line and a multiple ovulating male line of turkeys. The oestradiol output from small follicles in response to LH stimulation and the aromatase activity of the residual ovary were also compared. The multiple hierarchy of follicles in the male line was shown to consist of a series of follicles of a similar size and stage of physiological maturation. The follicles of the traditional line produced significantly greater quantities of oestradiol than those of the male line. Impaired oestradiol production may have resulted in the lower plasma oestradiol concentration observed in the male line. There was no difference in follicular progesterone output between the
\end{abstract}

traditional-line and male-line turkeys. The oestradiol output of whole small white follicles in response to LH stimulation was similar in the two lines and the depressed steroidogenesis of the male line was not changed. The aromatase activity of the small follicles was also lower in the male line, and there was no evidence that the male line ovary produced oestradiol in quantities proportional to its size. The results demonstrated that the hierarchy of follicles in the male line consisted of groups of follicles of similar mass and hormone output and indicated that selection for increased meat yield may have resulted in reduced ovarian steroidogenesis in male-line turkeys, in comparison with traditional, unselected turkeys.

\section{Introduction}

The ovary of avian species contains a hierarchy of follicles that have been recruited to develop to ovulation. This hierarchy normally consists of a single series of follicles of decreasing size that will be ovulated on consecutive days. For a turkey laying an egg a day, it has been shown that the ovary should contain no more than nine or ten of these hierarchical follicles (Hocking, 1987).

Male-line turkeys have been selected for high meat yield and have large ovaries with many more maturing ovarian follicles than unselected traditional-line turkeys and female lines that have been selected for egg production (Hocking, 1992; Melnychuk et al., 1994, 1997; Hocking and Bernard, 1998).

The small ovarian follicles and the ovarian stroma are the main sources of oestradiol in domestic hens (Senior and Furr, 1975) and contain about 50\% of the total ovarian aromatase activity (Armstrong, 1984). Oestradiol production by small white follicles has also been demonstrated in turkeys (Porter et al., 1989, 1991a,b). The developing ovarian follicles of domestic hens produce progesterone (Yu et al., 1992a) and production is greatest in granulosa cells from the largest preovulatory follicle (Huang et al., 1979).

As follicles mature, their steroid hormone output

*Correspondence

Email: paul.hocking@bbsrc.ac.uk changes from the predominant production of oestradiol to the production of progesterone (Marrone and Hertelendy, 1985; Robinson and Etches, 1986; Porter et al., 1991c). The male line ovary has many maturing follicles, which appear to be arranged in a multiple hierarchy characterized by follicles of similar masses, with double and triple follicles at each position. It is hypothesized that the steroid output from single and multiple follicular hierarchies should be different. The plasma oestradiol concentration is lower in the male line compared with the traditional line of turkeys (Buchanan et al., 1999) and there is no significant difference in plasma progesterone concentration between the two lines (Buchanan and Hocking, 1998). The multiple hierarchy of follicles and the larger ovary size of the male line did not result in high plasma hormone concentrations and this has led to the hypothesis that ovarian steroidogenesis is lower in the male line compared with the traditional line.

An alternative hypothesis to explain the lower plasma oestradiol concentration of the male line is that the maleline turkeys metabolize large quantities of oestradiol into another active oestrogen, such as oestrone, not detected by the oestradiol radioimmunoassay used by Buchanan et al. (1999). This hypothesis is supported by the work of Bacon et al. (1980), Brown et al. (1979) and Brown (1982) who showed that turkey plasma contains several different oestrogen metabolites. Therefore, the activity of aromatase, the enzyme responsible for the conversion of testosterone to oestradiol, in the residual ovary was estimated. If oestrogen production in male-line turkeys occurs 
to the same degree as it does in the traditional line, the male-line turkeys should metabolize a greater proportion of the oestradiol to another active oestrogen and this should be reflected in greater aromatase activity.

Plasma LH stimulates ovarian hormone production in turkeys and domestic hens (Huang et al., 1979; Hammond et al., 1981; Asem et al., 1983; Calvo and Bahr, 1983). Therefore, the responsiveness of the follicles to $\mathrm{LH}$ should influence their steroid hormone production and the sensitivity of the ovarian follicles to LH could differ between the two strains. Onegbesan et al. (1999) compared the steroid output in response to $\mathrm{LH}$ of granulosa cells of the three largest follicles from two lines of broiler breeders fed ad libitum or given restricted quantities of feed, and concluded that steroidogenesis was affected by both genetic selection and feed allowance.

Three experiments were carried out to compare ovarian steroidogenesis in traditional-line and male-line turkeys. The first experiment compared the output of oestradiol and progesterone from the various components of the ovaries of the two strains to test the hypothesis that steroidogenesis was reduced in male-line ovaries. Whole intact hierarchical follicles were incubated using the method described by $\mathrm{Yu}$ et al. (1992a) in domestic hens. A second experiment was carried out to measure the increase in oestradiol output from the small follicles of the residual ovary in response to incubation with $\mathrm{LH}$ in traditional-line and male-line turkeys to compare the sensitivity to LH stimulation between the two strains. The small white follicles were used as these are the most abundant and allowed follicles from each bird to be incubated at several concentrations of $\mathrm{LH}$. The third experiment addressed the hypothesis that the male-line ovary produces large amounts of oestradiol that are subsequently converted to other active oestrogens. The capacity of the residual ovary to produce oestrogens was measured using the aromatase activity assay described by Armstrong (1984, 1985).

\section{Materials and Methods}

\section{Animals}

The strains of turkeys (Meleagris gallopavo) used in these experiments were the Big 6 male line, obtained from British United Turkeys Ltd (Chester) and the traditional line Nebraska Spot (maintained at the Roslin Institute, Edinburgh). The turkeys were obtained at 1 day of age and were reared in floor pens containing wood shavings. They had constant access to water and conventional turkey diets, fed in suspended tubular feeders. The photoperiod was $14 \mathrm{~h}$ light: $10 \mathrm{~h}$ dark for the first 18 weeks, $7 \mathrm{~h}$ light:17 h dark for the next 11 weeks, and then photostimulation at 29 weeks and 4 days with 14 h light:10 h dark to stimulate sexual maturity.

\section{Experiment 1}

Female turkeys from the two strains were arranged in
12 identical pens, in a randomized design of six blocks, with each pen containing 4-6 turkeys. Two turkeys were selected randomly from each pen, at 6 weeks after photostimulation (12 turkeys per strain). Each turkey was killed between 09:00 and 12:00 $\mathrm{h}$ by an overdose of sodium pentobarbitone (Veterinary Drug Company, Falkirk). The total body weight was recorded and the ovaries were removed and washed in $0.01 \mathrm{~mol}^{\mathrm{PBS}} \mathrm{I}^{-1}$, $\mathrm{pH} 7.4$ (Sigma Chemical Company, Poole).

All ovarian follicles $>0.5 \mathrm{~g}$ were classed as hierarchical follicles and their individual masses were recorded. Any grossly atretic follicles were discarded. Incubations were performed as described by Yu et al. (1992a). Each hierarchical follicle was placed in an individual polystyrene pot containing incubation medium. The incubation medium used for all the follicles was Medium 199 (pH 7.2) containing $10 \mathrm{mmol}$ Hepes $\mathrm{I}^{-1}$ and $0.1 \%(\mathrm{w} / \mathrm{v})$ BSA (Sigma Chemical Company). The container sizes and volumes of medium used were dependent on follicle mass and allowed each follicle to move freely within the container while being completely covered in medium $(5 \mathrm{ml}$ for follicles < $5 \mathrm{~g} ; 10 \mathrm{ml}$ for follicles $5.1-10.0 \mathrm{~g} ; 15 \mathrm{ml}$ for follicles 10.1-15.0 g; $20 \mathrm{ml}$ for follicles $15.1-20.0 \mathrm{~g} ; 25 \mathrm{ml}$ for follicles 20.1-25.0 g; and $30 \mathrm{ml}$ for follicles > $25.1 \mathrm{~g}$ ).

The small follicles $<0.5 \mathrm{~g}$ were classified into three types on the basis of the classification used for domestic hens by Lee and Bahr (1994) but altered to account for the slightly larger size of turkey ovarian follicles. The classifications used were: small white follicles 1-3 $\mathrm{mm}$ in diameter; large white follilces 3-5 $\mathrm{mm}$ in diameter; and small yellow follicles $5-8 \mathrm{~mm}$ in diameter. Four follicles from each class were selected from each ovary and placed in a $5 \mathrm{ml}$ plasma tube containing $4 \mathrm{ml}$ incubation medium. The incubations were carried out for $3 \mathrm{~h}$ at $39^{\circ} \mathrm{C}$ in a shaking water bath. At the end of the incubation period, the tubes were immediately placed on ice and the medium was removed and stored at $-20^{\circ} \mathrm{C}$ for future radioimmunoassay.

As the theca and granulosa cells are located at the periphery of the follicles (Etches, 1996), the surface area of the follicles reflects the number of steroidogenic cells present. The surface area for each follicle was calculated from the follicle mass and density to allow the hormone output from the hierarchical follicles to be expressed relative to follicle surface area. The volume of a range of sizes of follicles (12 per turkey) from six male-line females that were killed 5 weeks after photostimulation was determined by placing each follicle in a measuring cylinder containing a known quantity of water and recording the volume of water displaced. Ovarian follicle density was then calculated from follicle mass and volume. The mean value obtained for follicle density was used subsequently to calculate the volume and surface area from the follicle mass of the individual follicles incubated in the experiments.

Analysis of variance was used to test for effects of block, strain and follicle size on the steroid hormone output and to test the differences in total hormone output between the two strains. The hormone output values were 
converted to natural logarithms before analysis to ensure normal distribution of the residuals.

\section{Experiment 2}

The second experiment was carried out 7 weeks after photostimulation. Twelve male-line and 24 traditional-line turkeys were selected from the same pens used in Expt 1. The turkeys were killed between 10:00 and 12:00 $\mathrm{h}$ as before. The ovary was immediately removed and rinsed in $0.01 \mathrm{~mol}^{\mathrm{PBS} \mathrm{I}^{-1}}$ (pH 7.4). The small white follicles (1-3 mm) were selected for this experiment as they are the most abundant follicle classification. Twenty small white follicles were harvested from each male-line turkey and paired with ten follicles from each of two traditional-line turkeys from the same experimental block.

Four follicles from each male-line turkey and pair of traditional-line turkeys were placed into $5 \mathrm{ml}$ plasma tubes with $4 \mathrm{ml}$ incubation medium containing $0,1,10,100$ or 1000 ng ovine $\mathrm{LH} \mathrm{m}^{-1}$ (Sigma Chemical Company). The incubation medium used was Medium $199(\mathrm{pH}$ 7.2) with $10 \mathrm{~mm}$ Hepes and $0.1 \%(\mathrm{w} / \mathrm{v})$ BSA. The plasma tubes were then incubated in a water bath at $39^{\circ} \mathrm{C}$ for $2 \mathrm{~h}$. At the end of the incubation period, the tubes were placed on ice and samples of the incubation medium were removed and stored at $-20^{\circ} \mathrm{C}$ for future radioimmunoassay.

Regression analysis was used to test for strain and dose differences in oestradiol output from the small follicles.

\section{Experiment 3}

Female turkeys from each strain were housed in 12 pens, with four turkeys in each pen, in a randomized design of six blocks. Nine weeks after photostimulation, two turkeys from each strain were selected randomly from each pen. The turkeys were blood sampled and killed between 10:00 and 12:00 $\mathrm{h}$ as before. The blood samples were transferred to heparin-coated $5 \mathrm{ml}$ blood collection tubes (Inverclyde Biologicals, Lanarkshire) and centrifuged at $2000 \mathrm{~g}$ for $10 \mathrm{~min}$. The body weight was recorded and the ovary was removed and rinsed in 0.01 mol PBS I-1. The hierarchical follicles (>0.5 g) were removed. All the small ovarian follicles $>2 \mathrm{~mm}$ were removed and classified as in Expt 1. The number of follicles in each classification was recorded and four follicles from each group were selected for incubation. The incubations were conducted as described by Armstrong (1984). Each follicle was incubated individually in plasma tubes containing $4 \mathrm{ml}$ incubation medium. The remainder of the ovary was divided into anterior and posterior sections at the site of attachment of the ovarian stalk (Waddington and Walker, 1988) and the two sections were weighed separately. All postovulatory follicles were removed from both parts of the ovary. Duplicate samples of anterior and posterior ovarian stroma (200-250 mg) were removed and their masses were recorded. Each sample was placed in $4 \mathrm{ml}$ medium (250 $\mathrm{mmol}$ sucrose $\mathrm{I}^{-1}, 1 \mathrm{mmol}$ EDTA $\mathrm{I}^{-1}$ and $20 \%(\mathrm{w} / \mathrm{v})$ glycerol; Armstrong, 1984) and homogenized for three ses- sions of $10 \mathrm{~s}$ each. Samples were then centrifuged for 10 $\min$ at $600 \mathrm{~g}$ and duplicate samples of $100 \mu \mathrm{l}$ supernatant were removed and placed in $4 \mathrm{ml}$ incubation medium.

All incubations were carried out in Medium 199 (pH7.2) containing $10 \mathrm{~mm}$ Hepes and $0.1 \%(\mathrm{w} / \mathrm{v})$ BSA. Tritiated testosterone $\left(1 \beta, 2 \beta-{ }^{3} \mathrm{H}(\mathrm{N})\right.$ testosterone, NEN Life Science Products Inc., Boston, MA) and testosterone were added to the medium to achieve a final concentration of $0.5 \mu \mathrm{mol}$ testosterone $\mathrm{I}^{-1}$ and a specific activity of 18.5 $\mathrm{MBq} \mathrm{I}^{-1}$. The incubations were carried out in a shaking water bath at $39^{\circ} \mathrm{C}$ for $2 \mathrm{~h}$. The samples were immediately placed on ice and the aromatase activity was calculated from the amount of tritiated water expressed as the quantity of oestradiol produced during the incubation period as described by Armstrong (1984).

Analysis of variance was used to test the effects of block, strain and follicle or ovarian tissue type on aromatase activity, and to evaluate differences in total ovarian aromatase activity and activity per gram body weight between the two strains.

\section{Radioimmunoassays}

The concentrations of oestradiol in the incubation medium of the samples from Expts 1 and 2 and the plasma samples from Expt 3 were measured by radioimmunoassay (Webb et al., 1985). The plasma samples were initially extracted using an antibody-Sepharose extraction procedure because of the high fat content of plasma from laying turkeys. The efficiency of the extraction procedure was $45.7 \%$. Samples from each experiment were analysed in single assays to eliminate interassay variability. The mean intra-assay coefficient of variation was $15.2 \%$ and the lowest sensitivity of the assay was $1.5 \mathrm{pg}$ per tube.

The concentration of progesterone in the medium of the samples from Expt 1 was measured by radioimmunoassay (Law et al., 1992). The samples were analysed in a single assay with an intra-assay coefficient of variation of $12.1 \%$ and lowest sensitivity of 25 pg per tube.

\section{Results}

The male-line turkeys had a heavier body weight, a larger residual ovary and a greater number of hierarchical follicles $(>0.5 \mathrm{~g}$ ) than the traditional-line turkeys in Expt 1 (Table 1). The means for Expts 2 and 3 were similar except that body weights for the male-line birds in Expt 3 were lower than they were in Expt 2 (5.4 \pm 0.09 and $18.4 \pm 0.43 \mathrm{~kg}$, respectively). Plasma oestrogen concentrations in Expt 3 were higher in the traditional line than they were in the male line (Table 1).

\section{Experiment 1}

The results of Expt 1 are presented as the total hormone output over the $3 \mathrm{~h}$ incubation period (Fig. 1). The mean output of oestradiol from successive follicles in the hier$\operatorname{archy}(>0.5 \mathrm{~g}$ ) for the two strains is shown (Fig. 1a) starting 
Table 1. Mean body weight, residual ovary mass, number of hierarchical follicles ( $>8 \mathrm{~mm}$ diameter) and plasma oestrogen concentration in traditional-line and male-line turkeys 6 weeks after photostimulation

$$
(n=12)
$$

\begin{tabular}{lcccc}
\hline Trait & Traditional line & Male line & SED & Significance \\
\hline Body weight $(\mathrm{kg})$ & 5.6 & 19.5 & 0.36 & $P<0.001$ \\
Residual ovary mass $(\mathrm{g})$ & 7.0 & 27.3 & 1.73 & $P<0.001$ \\
Number of follicles & 7.3 & 17.2 & 0.74 & $P<0.001$ \\
Oestrogen $\left(\mathrm{pg} \mathrm{ml}^{-1}\right)$ & 206.3 & 179.2 & 9.82 & $P<0.05$ \\
\hline
\end{tabular}

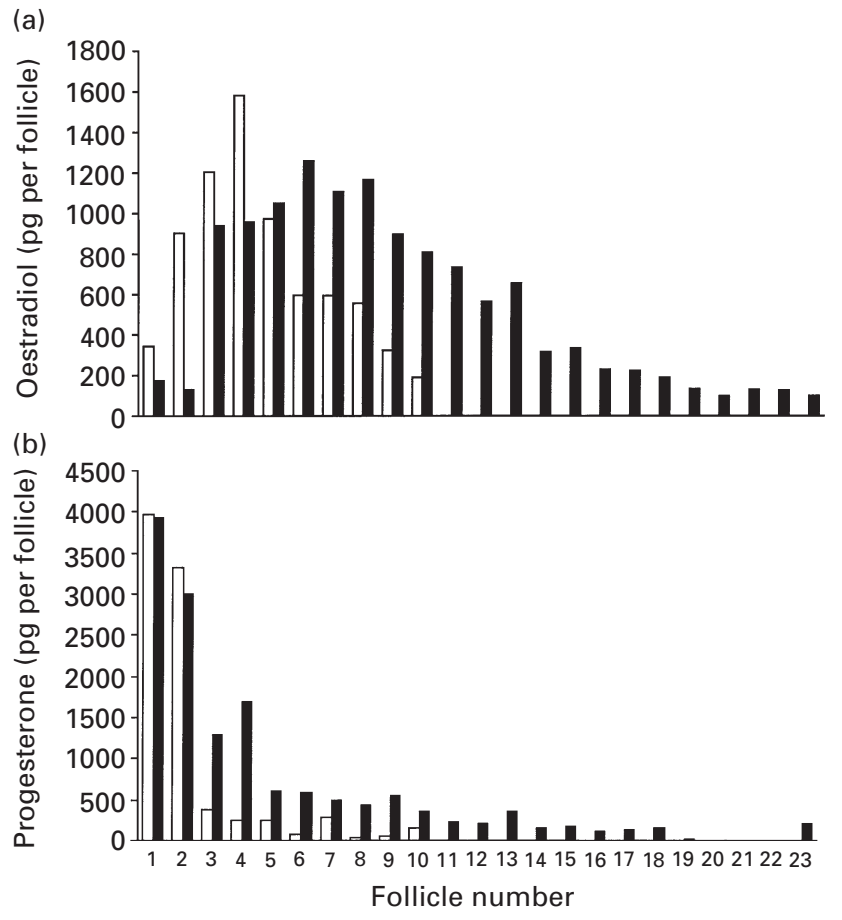

Fig. 1. Oestradiol (a) and progesterone (b) output per follicle numbered by follicle mass ( $1=$ heaviest follicle) in traditional-line $(\square)$ and male-line $(\square)$ turkeys $(n=12)$.

with the heaviest follicle. The progesterone output from the follicular hierarchy is presented in the same arrangement (Fig. 1b). It should be noted that as the number of follicles in the hierarchy varied for each turkey, the number of samples contributing to each data point declined after follicles 4 and 8 for the traditional and male lines, respectively.

Oestradiol output initially increased and then decreased as the follicle mass decreased (Fig. 1a). The oestradiol output was greatest from the fourth largest follicle of the traditional line and the sixth largest follicle of the male line. The progesterone output from each follicle decreased as the follicle mass decreased (Fig. 1b) in both the traditional and the male lines. In the traditional line, the first and second largest follicles produced most of the progesterone while, in the male line, the progesterone output was high from the four largest follicles.

Ovarian follicles in turkeys require 9-10 days to mature from selection into the yellow follicular hierarchy to ovulation (Hocking et al., 1987). In double-ovulating hens, the follicles are arranged in groups of two or more follicles of similar mass. These cohorts of follicles of similar mass had similar steroid profiles and, to permit comparisons of follicles at the same stage of maturation between the two lines, the follicles for each turkey were arranged into a maximum of ten hierarchical positions. There were $0.74 \pm 0.048$ and $1.70 \pm 0.050$ follicles at each position for the traditional-line and male-line turkeys, respectively $(P<0.001)$. The position in the hierarchy had no significant effect on the number of follicles at that position in either strain. The follicles were heavier in the male line than they were in the traditional line at every position in the hierarchy. The differences between the two strains in the mass of follicles decreased with decreasing follicle mass (a significant interaction between position in the hierarchy and strain; $P<0.001$ ).

There was no significant interaction between strain and hierarchy position for $\log _{\mathrm{e}}$ oestradiol or progesterone output per follicle. The position in the follicular hierarchy had a significant effect on the oestradiol output $(P<0.001)$ and, overall, there was a significantly greater output in the traditional line than in the male line $(P<0.001)$. The profile of steroid output per follicle for the two strains was similar when the follicles were arranged into a set hierarchy. The greatest output of oestradiol occurred at positions 3-5 in the hierarchy or 3-5 days before ovulation. Progesterone output was greatest in follicles at positions 1 and 2 of the hierarchy and was very low in the other follicles $(P<0.001)$. The mean output of progesterone was greater in the male line $(P<0.001)$ than it was in the traditional line.

The mean follicle density, determined from follicle mass and volume was $1.026 \pm 0.007 \mathrm{mg} \mathrm{mm}^{-3}(n=72)$. There was no significant difference in follicle density between the different turkeys $(n=6)$ and regression analysis showed that follicle mass had no significant effect on follicle density. The density was significantly different $(P<$ $0.001)$ from the value for broiler breeder hens $(0.781 \mathrm{mg}$ $\mathrm{mm}^{-3}$ ) reported by $\mathrm{Yu}$ et al. (1992a) and the higher value was used to calculate the surface area of each follicle. 
There was a significant interaction between strain and hierarchy position $(P<0.001)$ for oestradiol output expressed per $\mathrm{mm}^{2}$ follicle surface (Fig. 2a). The traditional line produced more oestradiol than the male line at each position but the difference decreased as the follicles approached ovulation. These results show that cellular oestradiol output was maintained at a similar rate throughout the first 6 days of development within the hierarchy and decreased in the last 3-4 days of follicle maturation in both the traditional-line and male-line turkeys. Expressing the progesterone output per $\mathrm{mm}^{2}$ follicle surface area resulted in no significant interaction between strain and position in the hierarchy. There was a significant effect of position in the hierarchy on cellular progesterone output $(P<0.001)$, but there was no significant difference between the two strains. The progesterone output per $\mathrm{mm}^{2}$ was greatest in follicles at the first and second positions in the hierarchy and was very low in the rest of the follicles. The progesterone output from the follicles at positions 1 and 2 was greater in the traditional line than it was in the male line, although this was not statistically significant.

The total outputs of oestradiol and progesterone from the follicular hierarchy of traditional-line and male-line turkeys are shown (Table 2). The total oestradiol output was greater in the male line than it was in the traditional line, whereas there was no difference in total progesterone output between the two lines. The total hormone output from the follicular hierarchy was divided by body weight to account for differences in plasma volume. When the oestradiol output was considered relative to body weight, it was significantly greater in the traditional line than it was in the male line, whereas there was no difference in progesterone output between the two strains (Table 2).

The mean output of oestradiol from the three classes of small ovarian follicle is shown (Fig. 3). There was no significant interaction between strain and follicle class in terms of oestradiol output. There was a significant effect $(P<0.001)$ of follicle classification as oestradiol output increased with follicle diameter. The output of oestradiol was significantly greater $(P<0.001)$ from the small ovarian follicles of the traditional line than from the small ovarian follicles of the male line. There was no significant difference in progesterone output between the different sizes of small follicle or between the traditional and male lines. (a)
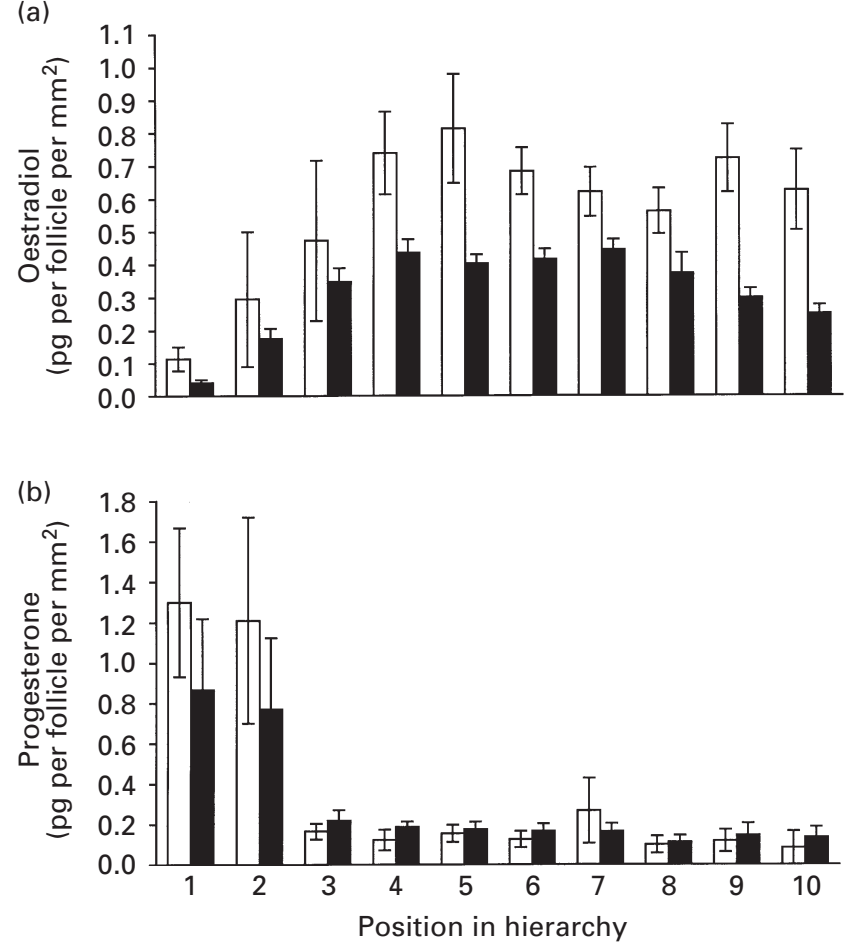

Fig. 2. Mean ( \pm SEM) oestradiol (a) and progesterone (b) output as a proportion of estimated follicle surface area at each of ten positions in the hierarchy of traditional-line $(\square)$ and male-line turkeys $(n=12)$.

The progesterone output from the small ovarian follicles was very low in both strains compared with the progesterone output from the hierarchical follicles or relative to the plasma progesterone concentrations.

\section{Experiment 2}

There was a significant effect of both dose $(P<0.01)$ and strain $(P<0.001)$ on oestradiol output from the small white follicles in response to stimulation by ovine $\mathrm{LH}$ over the $2 \mathrm{~h}$ stimulation period (Fig. 4). Oestradiol output increased in response to increasing concentrations of $\mathrm{LH}$,

Table 2. Mean total output of oestradiol and progesterone after a $3 \mathrm{~h}$ incubation of the yellow follicles $(>8 \mathrm{~mm})$ from traditional-line and male-line turkeys 6 weeks after photostimulation $(n=12)$

\begin{tabular}{lcccc}
\hline Steroid & Traditional line & Male line & SED & Significance \\
\hline Oestradiol & & & & \\
$\quad$ Total output $(\mathrm{ng})$ & 6.1 & 11.5 & 1.19 & $P<0.001$ \\
$\quad$ Output:body weight $\left(\mathrm{ng} \mathrm{kg}^{-1}\right)$ & 1.10 & 0.59 & 0.120 & $P<0.01$ \\
Progesterone & & & & \\
$\quad$ Total output $(\mathrm{ng})$ & 9.7 & 14.3 & 2.75 & $\mathrm{~ns}$ \\
$\quad$ Output:body weight $\left(\mathrm{ng} \mathrm{kg}^{-1}\right)$ & 1.58 & 0.75 & 0.420 & $\mathrm{~ns}$ \\
\hline
\end{tabular}

ns: not significant. 

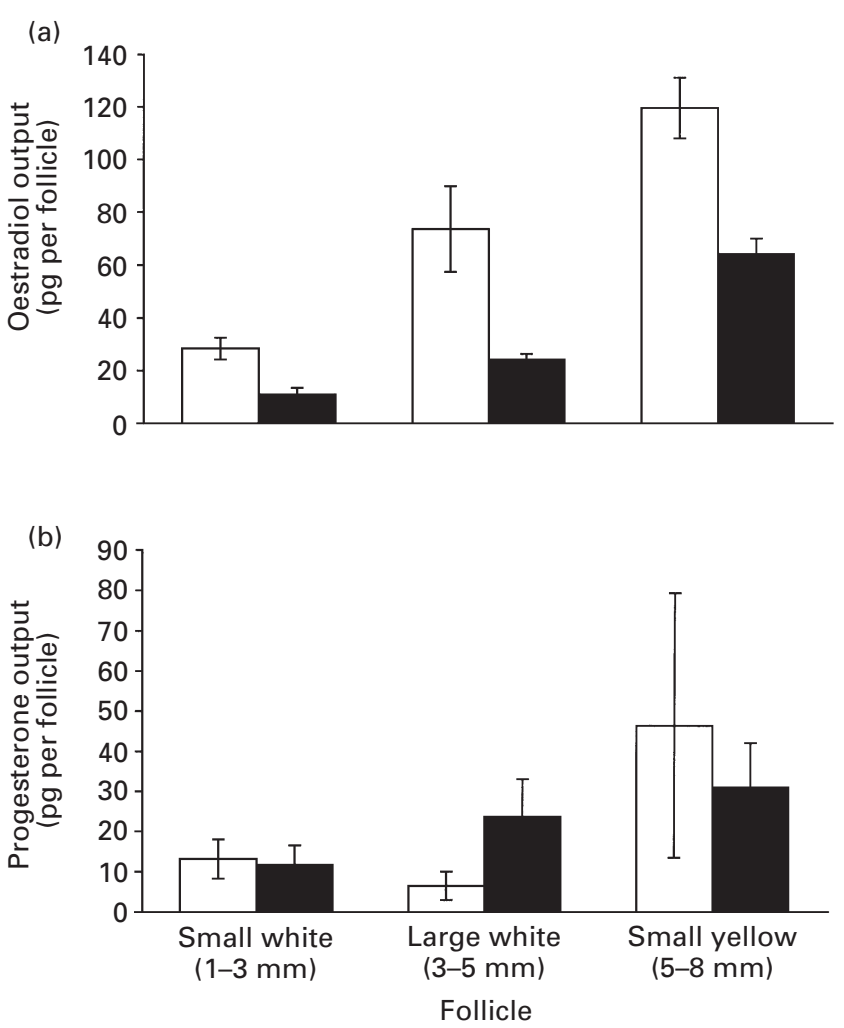

Fig. 3. Mean ( \pm SEM) oestradiol (a) and progesterone (b) output per follicle from three classes of small ovarian follicle in traditional-line ( $\square$ ) and male-line ( $\square$ ) turkeys $(n=12)$.

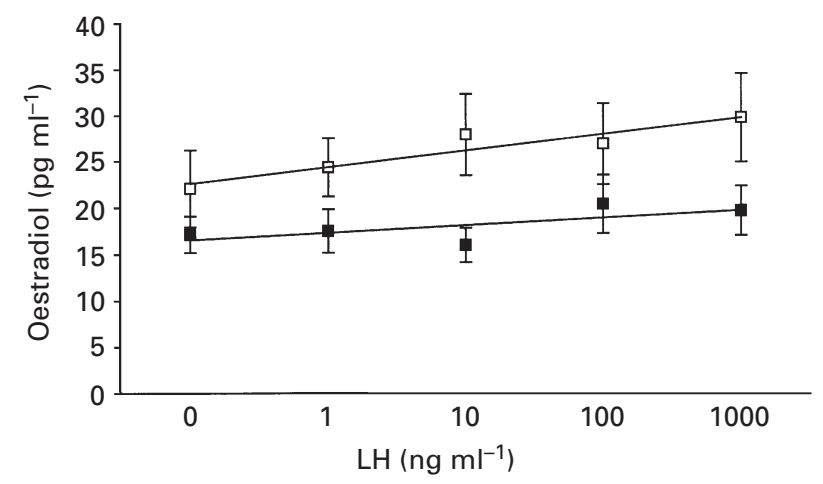

Fig. 4. Mean ( \pm SEM) oestradiol output from small white follicles in response to increasing concentrations of ovine $\mathrm{LH}$ in traditional-line ( $\square ; n=24)$ and male-line $(\boldsymbol{\square} ; n=12)$ turkeys.

and the traditional line showed a greater response than the male line, although the effect was not significant.

\section{Experiment 3}

The small follicles from the traditional line had significantly greater aromatase activity than did those from the male line (Fig. 5a). There was no interaction between (a)
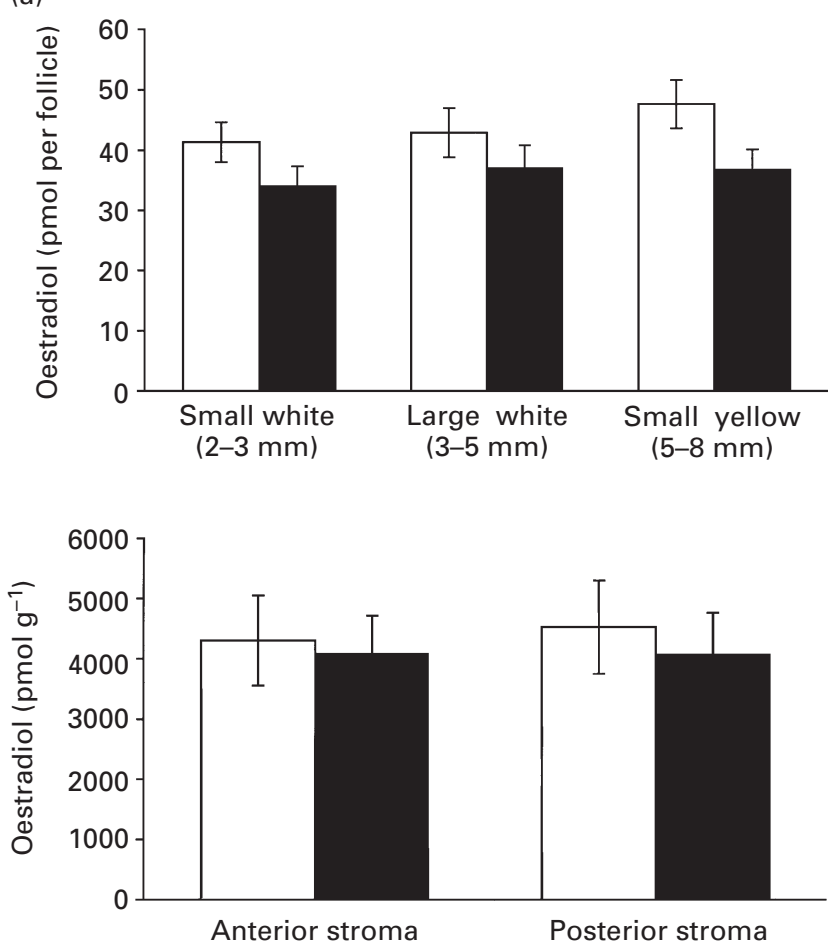

Fig. 5. Aromatase activity expressed as oestradiol output from three sizes of small white follicle (a) and from the anterior and posterior stroma of the residual ovary (b) in traditional-line ( $\square$ ) and male-line $(\boldsymbol{\square})$ turkeys $(n=12)$.

strain and follicle classification and no significant difference in the aromatase activity from the different classifications of small follicles. The mean outputs for the traditional and male lines, respectively were 43.9 and 35.8 pmol per follicle (SED $=3.92 ; P<0.001)$. There was no significant difference in aromatase activity between the anterior and posterior sections of ovarian stroma and no significant difference in the activity between the traditional and male lines (Fig. 5b).

The total aromatase activity of the residual ovary (small follicles $<0.5 \mathrm{~g}$ and ovarian stroma) was greater in the male line than it was in the traditional line (Table 3). When aromatase activity was considered relative to body weight, to correct for differences in plasma volume, there was no significant difference in the aromatase activity of the residual ovary between the traditional-line and maleline turkeys (Table 3).

\section{Discussion}

The results of Expt 1 showed that follicular oestradiol output decreased as the follicles approached maturity and that the majority of progesterone was produced by follicles of the two largest groups in the hierarchy. These results are in agreement with previous observations in turkeys (Porter 
Table 3. Mean total aromatase activity (measured as total oestradiol produced during a $2 \mathrm{~h}$ incubation period) of the residual ovary in traditional-line and male-line turkeys 9 weeks after photostimulation $(n=12)$

\begin{tabular}{lcccc}
\hline Aromatase activity & Traditional line & Male line & SED & Significance \\
\hline Total oestradiol (nmol) & 9.8 & 38.1 & 5.05 & $P<0.001$ \\
Activity:body weight (nmol oestradiol $\left.\mathrm{kg}^{-1}\right)$ & 1.82 & 2.05 & 0.217 & $\mathrm{~ns}$ \\
\hline
\end{tabular}

ns: not significant.

et al., 1991c) and domestic hens (Marrone and Hertelendy, 1985; Robinson and Etches, 1986). The follicles produce oestradiol predominately until about 4 days before ovulation, with the main production of progesterone occurring in the final 2 days before ovulation rather than 1 day before ovulation as in domestic hens. However, in the male line, the follicles are arranged in a hierarchy of pairs or triples that have similar masses and steroidogenic outputs. The follicles that make up the hierarchy are conventionally labelled F1, F2, F3, etc., according to their size, with the F1 follicle being the largest preovulatory follicle (Senior and Furr, 1975; Huang and Nalbandov, 1979; Bahr et al., 1983; Etches et al., 1983; Robinson and Etches, 1986; Johnson et al., 1987; Porter et al., 1991c; Yu et al., 1992a; RodriguezMaldonado et al., 1996). Onagbasen et al. (1999) and Yu et al. (1992b) investigated steroidogenesis in broiler breeder females fed ad libitum and on restricted diets with, respectively, a double and single hierarchy of follicles. Only the F1 follicle in food-restricted birds produced progesterone, while significant amounts of progesterone were produced by both the F1 and F2 follicles from birds fed ad libitum and Onagbasen et al. (1999) suggested that this finding indicated that the maturation of steroidogenesis was abnormal in broilers fed ad libitum. However, the present authors prefer the simpler explanation that there is a series of cohorts of follicles with similar steroidogenic activity that were recruited into the hierarchy on the same day. Labelling follicles of similar mass as F1.1, F1.2, F1.3 and F2.1, F2.2, etc., may help to avoid misleading representations about maturational processes when the problem of multiple ovulation is primarily one of increased recruitment into the hierarchy.

The steroid outputs of the hierarchical follicles measured in Expt 1 were comparable to those measured by $\mathrm{Yu}$ et al. (1992a), with the exception of the progesterone output from the largest preovulatory follicle, which was much lower than it is in the domestic hen. The progesterone outputs from all of the follicles were variable, as reflected by the large standard errors of the means. Plasma progesterone concentrations vary during the ovulatory cycle (Sharp et al., 1981) and the high variability of progesterone output was probably due to the individual turkeys being at different stages in their ovulatory cycle. It was not possible to take this into account in the experimental protocol owing to the low rate of egg production of turkeys.
The significant effect of strain on progesterone output reflects the greater production of progesterone from the male-line follicles at positions 3-6 in the hierarchy. However, the progesterone output is very low from these follicles in both strains and the difference between the strains was probably a consequence only of the size of the follicles, as indicated by the absence of differences when the progesterone output was expressed as a function of estimated surface area.

The lower mean oestradiol output in relation to the estimated surface area of the follicles of the male line compared with the traditional line indicates that oestradiol production in the follicular hierarchy of the male line was impaired. Oestradiol output per follicle from the small ovarian follicles was highest from the small yellow follicles and lowest from the small white follicles in both the traditional-line and male-line turkeys, consistent with the findings of Lee and Bahr (1994). The male-line turkeys had a lower output of oestradiol from the small ovarian follicles compared with traditional line turkeys, consistent with the suggestion that ovarian steroidogenesis was impaired in this strain. The low oestradiol output from both the follicular hierarchy and the small ovarian follicles of the male line may explain, in part, the lower plasma oestradiol concentration observed in the male line (Buchanan et al., 1999). Although the male line has a larger hierarchy of follicles and a heavier residual ovary, the reduced oestradiol output from these components results in a significantly lower total oestradiol output per kg body weight in the male line compared with the traditional line.

The results of Expt 2 showed that ovine LH-stimulated production of oestradiol from the small white follicles in both the traditional and the male lines. The small white follicles of the male-line turkeys produced less oestradiol at every concentration of $\mathrm{LH}$ used. The fitted line produced by the regression analysis was steeper in the traditional line, but there was no statistical evidence that the male-line turkeys are less responsive to $\mathrm{LH}$ stimulation than the traditional line. These results are consistent with the hypothesis that steroid production in ovarian follicles of the large turkey strain is lower than that of the smaller traditional line and that this is not likely to be the result of low circulating concentrations of $\mathrm{LH}$.

The results of Expt 3 showed that the aromatase activity of the small ovarian follicles was lower in the male line 
compared with the traditional line and confirmed the hypothesis that oestrogen synthesis in ovarian follicles was impaired in the male line. The magnitude of the aromatase activity was similar to that reported by Armstrong (1985) in the small ovarian follicles of domestic hens. The development of the ovarian follicles has been reported to differ between the anterior and posterior sections of the ovary (Waddington and Walker, 1988; Waddington and Hocking, 1993) and ovarian enzyme activity can vary in relation to the location of the tissue within the ovary (Armstrong, 1987). However, in the present study, there was no difference in the aromatase activity of the anterior and posterior sections of the ovary and no evidence that one line had a larger area of more active ovarian tissue than the other.

The greater total aromatase activity of the male-line residual ovary indicates that more oestrogen should be produced by the residual ovary of the male line. However, the oestrogen is released into a greater volume of plasma, and expressing the aromatase activity of the residual ovary as a function of body weight removed the difference between the two strains. These results also indicate that there should be no difference in the concentration of oestrogens in the plasma between the two strains, whereas plasma oestradiol concentration was lower in the male line than in the traditional line. In domestic hens, about $50 \%$ of the ovarian aromatase activity comes from the hierarchical follicles (Armstrong, 1984) but the aromatase activity of the follicular hierarchy was not measured in Expt 3. It is possible, but unlikely, that the aromatase activity of the hierarchical follicles would have been lower in the male line compared with the traditional line as was observed in the small ovarian follicles. The results of this experiment do not provide any evidence to support the hypothesis that the male line should have higher active oestrogen concentrations than the traditional line.

The results of the present study indicate that the low plasma oestradiol concentration of the male line compared with the traditional line was probably due to lower steroidogenesis in the ovarian tissue of the male line, even in the presence of additional $\mathrm{LH}$ stimulation. The relative amount of steroidogenesis occurring in the male line was not proportional to the amount of ovarian tissue present, and there was no evidence to indicate that the male line should have a higher total plasma oestrogen concentration than the traditional line. The multiple follicular hierarchy of the male line was shown to be physiological as well as anatomical. This finding should be considered when comparing the properties of follicles in birds with multiple hierarchies, such as commercial breeding turkeys and ad libitum-fed broiler breeders.

This work was funded by a CASE studentship from the Ministry of Agriculture, Fisheries and Food and British United Turkeys Ltd. Male-line turkey poults were kindly donated by British United Turkeys Ltd, Chester, UK. The authors thank Gerry Baxter for help with radioimmunoassays and David Armstrong for advice on measurement of aromatase activity.

\section{References}

Armstrong DG (1984) Ovarian aromatase activity in the domestic fowl (Gallus domesticus) Journal of Endocrinology 100 81-86

Armstrong DG (1985) Changes in aromatase activity in small ovarian follicles of the domestic fowl (Gallus domesticus) during growth and atresia Journal of Endocrinology 105 297-301

Armstrong DG (1987) Ornithine decarboxylase activity in small ovarian follicles from the laying hen (Gallus domesticus): a comparison of follicles from several regions of the ovary Journal of Endocrinology 112 183-187

Asem EK, Lintner F, Biellier HV, Burke WH and Hertelendy F (1983) Comparison of turkey $\mathrm{LH}(\mathrm{LH})$ - and ovine $\mathrm{LH}$-induced progesterone production in granulosa cells of the turkey (Meleagris gallopavo) and of the domestic fowl (Gallus domesticus) General and Comparative Endocrinology 52 445-451

Bacon WL, Brown KI and Musser MA (1980) Changes in plasma calcium, phosphorus, lipids, and estrogens in turkey hens with reproductive state Poultry Science 59 444-452

Bahr JM, Wang SC, Huang MY and Calvo FO (1983) Steroid concentrations in isolated theca and granulosa layers of preovulatory follicles during the ovulatory cycle of the domestic hen Biology of Reproduction 29 326-334

Brown KI (1982) Four turkey plasma and ovarian peaks detected with anti17ß-estradiol-6BSA serum Poultry Science 611427 (Abstract)

Brown KI, Long DW, Bacon WL and Braselton WE (1979) Evidence for the presence of 15-hydroxylated estrogens in the peripheral plasma of the laying turkey General and Comparative Endocrinology 39 552-560

Buchanan S and Hocking PM (1998) Changes in plasma oestradiol and LH during the ovulatory cycle in a multiple ovulating and a single ovulating strain of turkey Journal of Reproduction and Fertility Abstract Series 2224

Buchanan S, Robertson GW and Hocking PM (1999) The relationships between vaginal collagen, plasma oestradiol and uterine prolapse in turkeys Research in Veterinary Science 67 153-157

Calvo FO and Bahr JM (1983) Adenylyl cyclase system of the small preovulatory follicles of the domestic hen: responsiveness to follicle-stimulating hormone and LH Biology of Reproduction 29 542-547

Etches RJ (1996) The Ovary. In Reproduction in Poultry pp 125-165 CAB International, Oxford

Etches RJ, MacGregor HE, Morris TF and Williams JB (1983) Follicular growth and maturation in the domestic hen (Gallus domesticus) Journal of Reproduction and Fertility 67 351-358

Hammond RW, Burke WH and Hertelendy F (1981) Influence of follicular maturation on progesterone release in chicken cells in response to turkey and ovine gonadotrophins Biology of Reproduction 24 1048-1055

Hocking PM (1987) Observations on the size of the follicular hierarchy in the turkey hen and a case of arrested follicular growth British Poultry Science 28 755-757

Hocking PM (1992) Genetic and environmental control of ovarian function in turkeys at sexual maturity British Poultry Science 33 437-448

Hocking PM and Bernard R (1998) Comparative development of the ovary and production, fertility and hatchability of eggs from traditional turkeys and a contemporary male line fed ad libitum or restricted British Poultry Science 39 291-297

Hocking PM, Gilbert AB, Walker M and Waddington D (1987) Ovarian follicular structure of White Leghorns fed ad libitum and dwarf and normal broiler breeders fed ad libitum or restricted until point of lay British Poultry Science 28 493-506

Huang ES and Nalbandov AV (1979) Steroidogenesis of chicken granulosa and theca cells: in vitro incubation system Biology of Reproduction 20 442-453

Huang ES, Kao KJ and Nalbandov AV (1979) Synthesis of sex steroids by cellular components of chicken follicles Biology of Reproduction 20 454-461

Johnson PA, Stoklosowa S and Bahr JM (1987) Interaction of granulosa and theca layers in the control of progesterone secretion in the domestic hen Biology of Reproduction 37 1149-1155 
Law AS, Baxter G, Logue DN, O'Shea T and Webb R (1992) Evidence for the action of bovine follicular fluid factor(s) other than inhibin in suppressing follicular development and delaying oestrus in heifers Journal of Reproduction and Fertility 96 603-616

Lee KA and Bahr JM (1994) Utilization of substrates for testosterone and estradiol-17 $\beta$ production by small follicles of the chicken ovary Domestic Animal Endocrinology 11 307-314

Marrone BL and Hertelendy F (1985) Decreased androstenedione production with increased follicular maturation in theca cells from the domestic hen (Gallus domesticus) Journal of Reproduction and Fertility 74 543-550

Melnychuk VL, Renema RA, Robinson FE and Emmerson DA (1994) Reproductive development in the turkey hen: comparison between male and female lines Proceedings of the 9th European Poultry Conference Glasgow pp 318-319

Melnychuk VL, Robinson FE, Renema RA, Hardin RT, Emmerson DA and Bagley LG (1997) Carcass traits and reproductive development at the onset of lay in two lines of female turkeys Poultry Science $\mathbf{7 6}$ $1197-1204$

Onagbesan OM, Decypere E, Leenstra F and Elhard DA (1999) Differential effects of amount of feeding on cell proliferation and progesterone production in response to gonadotrophin and insulin-like growth factor 1 by ovarian granulosa cells of broiler breeder chicken selected for fatness or leanness Journal of Reproduction and Fertility $11673-85$

Porter TE, Hargis BM, Silsby JL and El Halawani ME (1989) Enhanced progesterone and testosterone secretion and depressed estradiol secretion in vitro from small white follicle cells of incubating turkey hens General and Comparative Endocrinology 74 400-405

Porter TE, Silsby JL, Behnke EJ, Knapp TR and El Halawani ME (1991a) Ovarian steroid production in vitro during gonadal regression in the turkey I. Changes associated with incubation behaviour Biology of Reproduction 45 581-586

Porter TE, Silsby JL, Behnke EJ, Knapp TR and El Halawani ME (1991b) Ovarian steroid production in vitro during gonadal regression in the turkey II. Changes induced by forced molting Biology of Reproduction 45 587-591

Porter TE, Hargis BM, Silsby JL and El Halawani ME (1991c)
Characterization of dissimilar steroid productions by granulosa, theca interna and theca externa cells during follicular maturation in the turkey (Meleagris gallopavo) General and Comparative Endocrinology $841-8$

Robinson FE and Etches RJ (1986) Ovarian steroidogenesis during follicular maturation in the domestic fowl (Gallus domesticus) Biology of Reproduction 35 1096-1105

Rodriguez-Maldonado E, Velazquez PN, Juarez-Oropeza MA and Pedernera E (1996) Steroid metabolism in theca externa cells from preovulatory follicles of domestic hen General and Comparative Endocrinology 101 173-179

Senior BE and Furr BJA (1975) A preliminary assessment of the source of oestrogen within the ovary of the domestic fowl, Gallus domesticus. Journal of Reproduction and Fertility 43 241-247

Sharp PJ, Lea RW, Chadwick A and Lake PE (1981) Concentrations of plasma luteinising hormone, prolactin, progesterone and androgens during the ovulatory cycle of the turkey British Poultry Science 22 375-383

Waddington D and Hocking PM (1993) Modification of intra-ovarian follicular distributions in broiler breeder hens by ad libitum or restricted feeding British Poultry Science 34 777-784

Waddington D and Walker MA (1988) Distribution of follicular growth, atresia and ovulation in the ovary of the domestic hen (Gallus domesticus) at different ages Journal of Reproduction and Fertility 84 223-230

Wells JW, Culbert J, Gilbert AB, Walker MA and Davidson MF (1985) LH stimulation of oestradiol production in vitro by small ovarian follicles in the hen (Gallus domesticus) IRCS Medical Science 131091

Yu MW, Robinson FE and Etches RJ (1992a) Quantification of ovarian steroidogenesis in the domestic fowl by incubation of intact large follicles Poultry Science 71 346-351

Yu MW, Robinson FE and Etches RJ (1992b) Effect of feed allowance during rearing and breeding on female broiler breeders 3. Ovarian steroidogenesis Poultry Science 71 1762-1767

Revised manuscript received 8 August 2000.

Accepted 7 September 2000. 